\title{
Enhanced coefficient of performance by effective suction line cooling- an experimental report
}

\author{
G. Edison ${ }^{1}$, A. Suresh ${ }^{2}$ and K. Narayana Rao ${ }^{3}$ \\ ${ }^{1}$ School of Mechanical and Building Sciences, VIT University, Vellore-632014, India \\ ${ }^{2}$ Vignan Institute of Technology and Sciences, Hyderabad - 508284, India \\ ${ }^{3}$ Osmania University, Hyderabad - 500007, India \\ edison.g@vit.ac.in,s4akella@yahoo.com; s4akella@gmail.com,knasa2k2@yahoo.com
}

\begin{abstract}
The present paper is concerned with theoretical and experimental study and development of effective suction gas heat exchanger for hermetically sealed compressor. A single tube counter flow heat exchanger had been used, where water itself had been taken as a coolant. Energy consumption parameters as well as COP values have been obtained analytically for both the cases. Energy consumption parameter is $12 \%$ less as an average for a heat exchanger attached system compared to the system with out heat exchanger in a time span of 90 minutes. COP values obtained with heat exchanger are firmly better than that of the values with out Heat exchanger. COP values observed to be $7 \%$ higher for a heat exchanger coupled system compared to the system with out heat exchanger in the same time span of 90 minutes. In the present scenario where systems optimization is a necessity the present work would be useful in developing a energy efficient system with few modifications. This work would be useful to tackle the heat transfer related issues present in many gas compressors used in pumping and process industries.
\end{abstract}

Keywords: Suction line cooling, Heat exchanger, COP, Refrigeration, T-S plot, Density, Refrigerant.

\section{Introduction}

The compressor is one of the main parts of an air conditioner; it is thus the first component of the refrigerator to be modeled. Compressor would consume less work when its inlet temperature is low. This is because when the inlet temperature is reduced suction path gas superheating losses are reduced. The density decrease due to suction gas heating and mixing is a very important factor affecting mass flow rate, and can be characterized by a single parameter, the effectiveness of heat transfer driven by the difference between the temperature at the suction line and the discharge port.

Researchers in many countries have been involved in developing refrigeration systems that deal with the drawbacks of conventional systems. The need for rational energy consumption is a worldwide concern and the quest for reducing energy wasting comprises not only an optimization of energy use but also how to lower consumption. Besides, these goals must be achieved without compromising comfort and other advantages brought by the use of energy, and without affecting efficiency and quality of installations.

The type of compressors used in domestic air conditioner is usually the reciprocating. Reciprocating compressors are mainly used as far as low thermal power is concerned. In the literature various performance losses of a reciprocating compressor are sighted. Suresh Akella et al. (1986) in an experimental method for design and performance evaluation of a hermetic compressor and John J. Jacobs (1978) of Carlyle Compressor Company in his analysis and experimental techniques for evaluating compressor performance losses, briefed the theoretical analysis of the losses.

Gas to wall heat transfer model has been developed to improve the thermal energy analysis. Heat transfer model assume important role in the compressor performance when it has to work over a wide range of operating conditions. The losses encountered in the working of a compressor are suction gas super heating, suction path gas heating, mean manifold pressure drop, manifold pressure pulsation, valve dynamics, piston ring blow-by and clearance volume.

Heat transfer which occurs during suction path i.e after it leaves the suction pipe, before the suction valve closes on the induction stroke, reduces the fluid density. The main factors affecting the volumetric efficiency of reciprocating compressors are analyzed by McGovern.(1990). One dimensional and a two-dimensional gas flow model and a simplified heat transfer calculation are introduced in Fluid Dynamics, Heat Transfer and Valve Dynamics in a Reciprocating Compressor to capture the main characteristics of the compressor by Roland Aigner et al.(2007).

\subsection{Refrigeration systems}

The difference between the vapour compression refrigeration system and the vapour absorption system is in the manner in which external heat is added to the vaporized refrigerant to increase its thermal level above that of the atmosphere in the condenser. 
The compressor in the compression system is replaced by absorber, generator and a pump in the vapour absorption system.

Warm, high pressure liquid refrigerant (R-12) from the receiver flows into the evaporator coils through the liquid control device(expansion valve).In the evaporator the pressure drops, due to the section of the compressor and the liquid refrigerant boils to a gas, absorbing its latent heat of vaporization from the substance being cooled, which surrounds the evaporator coils.

The compressor picks up this cold low pressure gas from evaporator and discharges it into the condenser at high pressure and temperature. The condenser is either air or water cooled. Here the hot high pressure refrigerant gas gives up its latent heat of condensation to the cooling medium and returns to the liquid state.

The pressure of the refrigerant in the evaporator is lowered until the addition of heat will cause the refrigerant to boil to a required evaporator temperature. The pressure of this low temperature gas must then be raised by the compressor to a point at which it will condense to a liquid at ordinary air or water temperature.

\subsection{Compressor performance losses}

The losses encountered in the working of a compressor are suction gas super heating, suction path gas heating, mean manifold pressure drop, manifold pressure pulsation, valve dynamics, piston ring blow-by and clearance volume. Suction path gas superheating occurs as it passes through the suction path, the motor and the crankcase. As suction superheating increases, effective performance of compression process decreases which would also increases the power to maintain a constant flow rate at a given operating pressure differential increases.

Mean manifold pressure drop occurs due to the flow restrictions on the low side of the compressor. Magnitude of these flow restrictions can be measured with a manometer tube or two transducers capable of measuring absolute pressure. Manifold pressure pulsation occurs in the suction manifold can be used to improve the performance by affecting the valve motion, under pressure, power and capacity. They can delay the valve motion and / or reopen the valve after it has closed. Valve port losses can be reduced by attaining within the valve port area and/or the port entrance, port optimization with strain gauge type pressure transducers mounted in a compressor and on a calorimeter.

Reduction of suction path gas super heating loss is the main concern in this present work. To reduce the suction gas superheating a single tube heat exchanger is incorporated. It consists of an inner tube and outer tube. Through the inner tube the hot fluid flows through the outer tube the coolant flows in opposite direction. The heat exchanger reduces the inlet temperature of the compressor. The present work is to compare the theoretical and experimental study and development of effective suction gas heat exchanger for hermetically sealed compressor.

\subsection{Heat transfer in reciprocating compressors}

Heating is an undesirable effect of the compression process at least as far as compressors are concerned and heat transfer is nature's way of driving systems towards stability. This has not only provided food for thought for researchers trying to understand its influence and quantity its effects, but also challenged designers to mitigate its impact and develop safe and efficient designs. Also, just as any other unwanted phenomenon would spur curiosity and inventiveness, this has led to the development of a host of new materials both metallic as well as non-metalic to withstand the vagaries of high temperatures, is addition to the toxic environment present in many gas compressors used in pumping and process industries.

This work would be useful and an attempt to tackle the heat transfer related issues present in many gas compressors used in pumping and process industries. This work is an attempt to present some of the problems created by this unwanted phenomenon, reviews the contributions of some of the past investigators, and kindles more interest for furthering the advancement of compressor technology.

Until recently, heat transfer in reciprocating compressors had assumed a back burner role. The recent trend in energy consciousness has rekindled interest and generated considerable debate and contradictory opinions about the extent of influence of heat transfer on compressor performance. Heat transfer does not just affect the performance but also the design, operation and reliability of compressors. One of the main limitations in the design of compact single stage compression systems is the inability to control the large temperatures generated during the compression process.

Temperature also becomes a defining parameter in the operation of many compressors. In many cases, the operational pressure ratio needs to be limited depending on the inlet temperature (which is beyond the control of the user), in order to keep the discharge temperature within safe limits. Also, unloaded operation, which results in higher than normal temperatures, may be forbidden because of temperature limitations.

From the reliability point of view, temperature affects many of the material properties in addition to dimensional stability and integrity of the component itself. In as far as compressor performance is concerned, it is well known that heating and cooling of 
the gas are unavoidable events associated with compression and expansion inside reciprocating compressor cylinders.

An obvious result of this is the transfer of heat from and to the gas which also occurs in an unsteady manner. It has both advantages as well as disadvantages. In spite of its complexity, the phenomenon of heat transfer has attracted the attention of many more investigators in the area of internal combustion engine than compressors. This might be partly due to the dominant role played by heat transfer in an engine, while converting the heat content of the fuel into mechanical energy.

However, as compressor efficiencies are approaching their limits and energy deficiencies have started looming on the horizon, designers have started searching for energy savings a whatever cost. This is driving researchers to take a second look at the effect of heat transfer on the performance of compressors.

\subsection{Suction line cooling}

The extent of suction path gas heating in this case depends on various factors like speed of the compressor, which determines the residence time of the gas entering the unloaded end in the suction passage; ratio of the swept volume to the cylinder suction passage volume, which determines the amount of gas pushed from the unloaded end which enters the loaded end during the subsequent stroke; number and location of the suction ports with reference to the inlet nozzle., which determines the flow pattern into the loaded end etc. in addition to unloading an end, suction gas heating could also be caused by leakage past piston rings and valves, which is of serious concern in high pressure ratio compressors, and frictional heating near the rider bands and packing rings, which are of main concern in non lubricated, high speed compressors.

Even from the reliability point of view, high temperatures cause serious concern. For example, impact strength of a valve plate or the sealing effectiveness of a piston or packing ring depends on the temperature.

Cylinder lubricants may not just lose their viscosity, but also may break up leading to deposition on valve plates and passages causing inefficient operation even failure. Any such deposition of a lubricant, or refrigeration compressors, or water/liquid droplets/slugs in compressors operating at relatively low temperatures, would pose a further challenge to development of reliable wall heat transfer correlations.

In addition, the lubricant may also vaporize and contaminate the discharge gas thus affecting the downstream process, unless the oil vapors are removed by using expensive filters. It is also not uncommon for cylinders and pistons to loose their concentricity because of poor lubrication, leading to operational failure and even irreparable damage to the components as a result of ceasing of the parts.

\subsection{Heat exchanger -mean temperature difference}

A direct contact type of heat exchanger is one in which the two fluids are not separated by a wall. Very often in direct contact heat exchangers, the process of heat transfer is also accompanied by mass transfer.

The heat transfer from one fluid to another fluid is given by the expression

$$
\mathrm{Q}=\mathrm{AU} \Delta \mathrm{Tm}
$$

Where $\mathrm{Tm}$ is known as the mean temperature difference and $\mathrm{U}$ is known as over all heat transfer coefficient.

An exchanger provides the surface area necessary to transfer energy from one fluid stream to another. The temperatures of all fluids may change while flowing through the exchanger. The energy transferred between the streams results in a change in a temperature of each fluid stream if neither fluid is undergoing a phase change.

As a result of the gradual change in the temperature level in an exchanger, the temperature difference across the heat transfer barrier vary over the length of the exchanger. The relation between the exchanger mean temperature difference and four extreme fluid temperatures is considered for several important arrangements.

The following assumptions are made for the derivation of LMTD.

- The overall heat transfer coefficient $\mathrm{U}$ is a c constraint.

- The mass flow rate of each fluid is constant.

- The specific heat of each fluid is constant.

- There is no phase change either of the fluid during the heat transfer.

- $\quad$ External heat losses are negligible.

If the flow length is for a parallel flow then the temperature distribution for hot and cold fluid will be, Let $\mathrm{mh}=$ Mass of the hot fluid flowing per unit time, $\mathrm{C}_{\mathrm{Ph}}=$ Specific heat of hot fluid, $\mathrm{T}_{\mathrm{hi}} \& \mathrm{~T}_{\mathrm{ho}}$ are the inlet and outlet temperatures of the hot fluid, $\mathrm{m}_{\mathrm{c}}=$ Mass of the cold fluid flowing per unit time, $\mathrm{C}_{\mathrm{pc}}=$ Specific heat of cold fluid, Tci \& Tco are the inlet and outlet 
temperatures of the cold fluid respectively, Assuming $\mathrm{Cph}=\mathrm{Cpc}$ in deriving the LMTD equation.

LMTD for parallel flow is given by the equation

$$
\text { LMTD }=\theta_{\mathrm{i}}-\theta_{0} / \log _{\mathrm{e}}\left(\theta_{\mathrm{i}} / \theta_{\mathrm{o}}\right)
$$

wwWhere,

$$
\begin{aligned}
& \theta_{\mathrm{i}}=\mathrm{T}_{\mathrm{hi}}-\mathrm{T}_{\mathrm{ci}} \\
& \theta_{0}=\mathrm{T}_{\mathrm{ho}}-\mathrm{T}_{\mathrm{co}}
\end{aligned}
$$

Effectiveness-NTU method is based on evaluating the heat exchanger performance in terms of three dimensionless parameter Viz. Effectiveness (E), number of transfer units (NTU) and capacity rate ratio (C).

The above three parameters different as below:

1) Effectiveness $=$ Actual heat transfer/Maximum possible heat transfer.

$=\mathrm{Q} / \mathrm{Q} \max$

The actually heat transfer may be computed by calculating either the heat lost by the hot fluid are heat gained by the cold fluid.

i.e., $\mathrm{Q}=\mathrm{Ch}(\mathrm{Thi}-\mathrm{Tho})=\mathrm{Cc}(\mathrm{Tco}-\mathrm{Tci})$

Q Max. Can be calculated as

Q max. $=$ Cc min. (Thi-Tci)

2) Number of transfer units (NTU):

It is given by the expression

$$
\mathrm{NTU}=\mathrm{UA} / \mathrm{C}_{\text {min. }}
$$

It is dimensionless number. The physical significance of this number should be noted. Since it is proportional to area, it is a measure of the size of the heat exchanger.

3) Capacity rate ratio $(\mathrm{C})$ :

It is defined as the ratio of heat equivalent of smaller to the heat equivalent of bigger. It is given by the expression.

$$
\mathrm{C}=(\mathrm{mcp}) \mathrm{s} /(\mathrm{mcp}) \mathrm{b} \text {. }
$$

Effectiveness for the parallel flow heat exchanger:

The effectiveness for the parallel flow heat exchanger is derived as

$$
\mathrm{E}_{\text {parallel }}=\left[{ }_{1}-(\mathrm{e})^{-\mathrm{UA}(1 / \mathrm{cc}+1 / \mathrm{ch})]} /\left[\mathrm{C}_{\min }\left(1 / \mathrm{c}_{\mathrm{c}}+1 / \mathrm{c}_{\mathrm{h}}\right)\right.\right.
$$

\section{Experimental procedure and experimental setup}

A single tube counter flow heat exchanger is incorporated in between the evaporator and the compressor.

- The vapor refrigerant coming out through the evaporator enters the inner tube of the heat exchanger. Fig. 1

- The coolant kept in a vessel at an elevated position so that it is circulated by gravity it self. The amount of coolant is regulated by the knob fitted along the tube (Plate 1).

- The coolant passing through the outer tube of the heat exchanger absorbs the heat of the refrigerant.

- By setting the mass flow of the coolant required temperature difference is obtained. Hence, the temperature of the refrigerant is reduced.

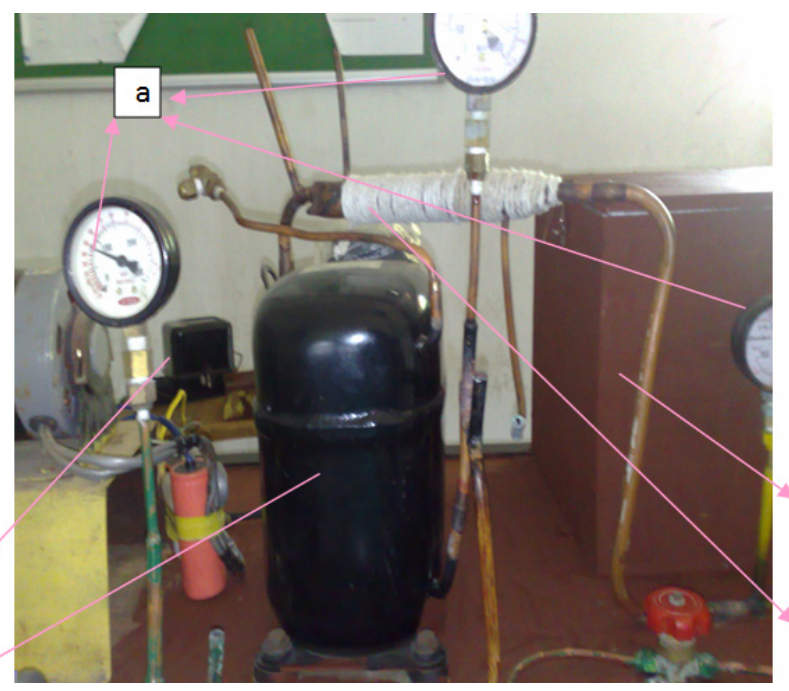

Plate 1. Reciprocating Compressor with Heat

Exchanger set up

a. Pressure gauges; $\mathbf{b}$. Reciprocating Compressor;

c. Heat exchanger along suction line;

d. Evaporator box;

e. Energy meter 
- This refrigerant, whose temperature is less than that without a heat exchanger, enters the compressor. Thus reductions in the suction path gas superheating losses are minimized.

- Temperatures and pressures are noted down using thermo couples and pressure gauges fitted before and after every element.

- Calculations for the COP and energy input are found out using formulae given in the equations (1) to (10).

- Experiment is being conducted with and with out heat exchanger.Fig.2. All the pressures and temperatures are noted down using the gadgets provided. Experiments are repeated to check the validity of the values. Every time the values are taken only after the system reached the steady state (Fig.1-2).

\section{Results and discussions}

Using the heat exchanger an average of $2^{0}$ temperature difference is maintained throughout the duration of experimentation. The variation of pressure after evaporation i.e. before compression, with heat exchanger $\&$ with out the heat exchanger set up is noted down, result compared. The affect of this is on mass flow and volumetric efficiency is discussed and interpreted. The effect on coefficient of performance is compared in both the cases with time. It is observed that performance with a heat exchanger is always above than the performance with out a heat exchanger. In both the cases of with and with out a heat exchanger the energy consumption parameter variation with time is investigated. Incase of suction path cool with a heat exchanger the energy consumption parameter is low compared to the value of energy consumption parameter with out a heat exchanger set up (Fig. 3-8).

Fig.1. Coolant passing through the heat exchanger

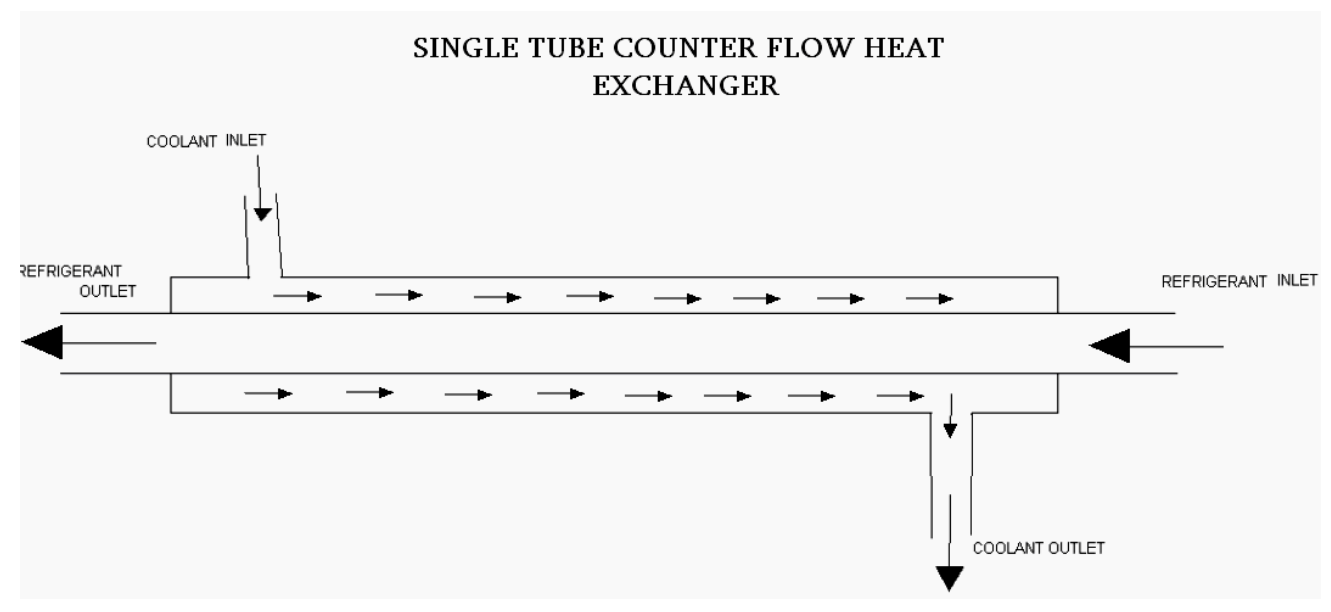

Fig.2. Cycles with and without the heat exchanger

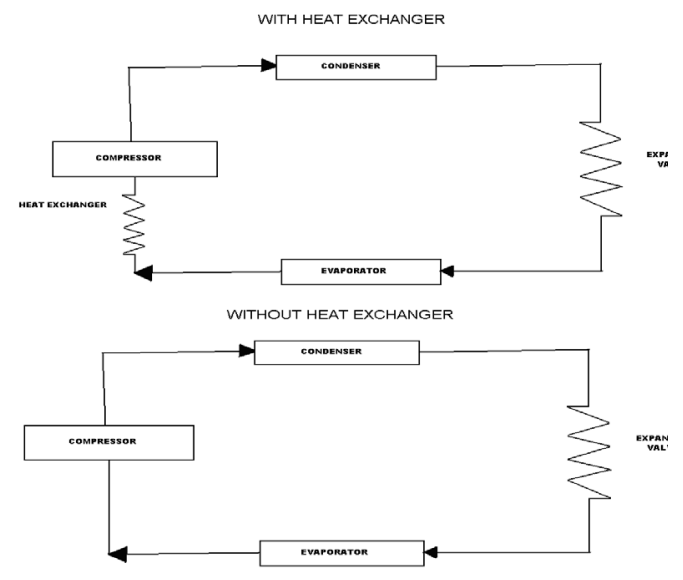

- $\quad$ By providing the heat exchanger the temperature inlet to the compressor is less, i.e. an average of $2^{0}$ temperature difference is maintained throughout the duration of experimentation. This confirms the effectiveness of water cooled heat exchanger (Ref. Fig. $3 \& 4)$. 
Fig.3. Temperature before compression T1, versus time t(with and without heat exchanger)

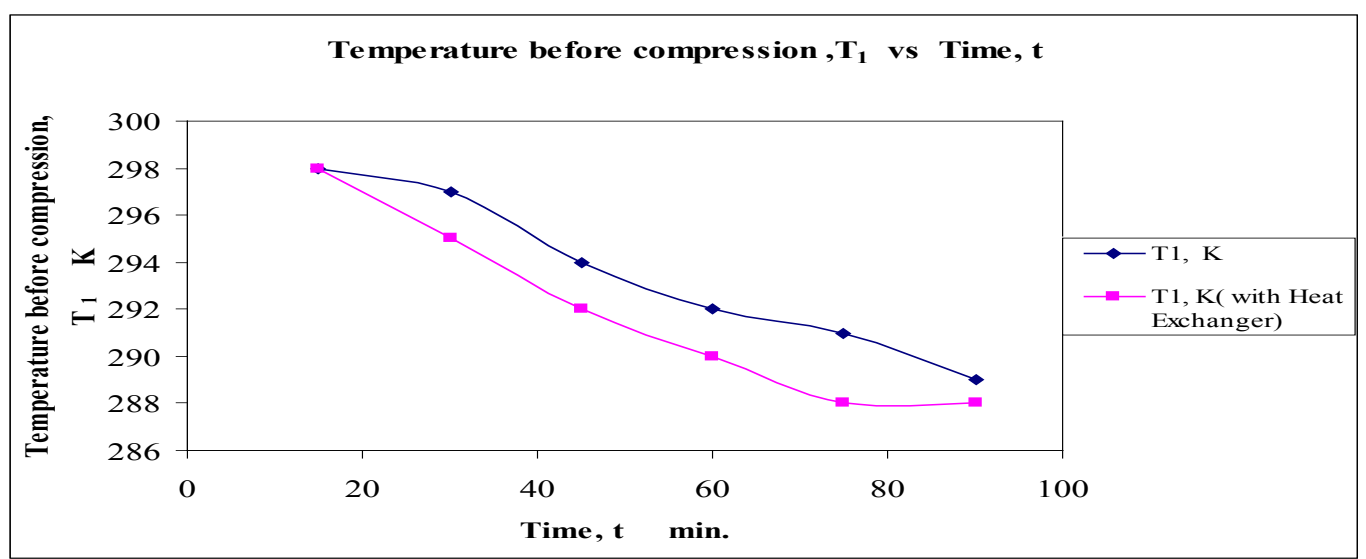

- The pressure after evaporation i.e. before compression is increasing with heat exchanger set up on vapour compression refrigeration set up, during the time of experimentation, while the pressure remained constant when the instrument was operated with out the heat exchanger. This is due to the enhanced mass flow i.e due to enhanced density of the flow. By this it can even be concluded that there will be hike in the volumetric efficiency as well.

Fig.4. Pressure before compression P1, versus time, $t$ (with and without heat exchanger)

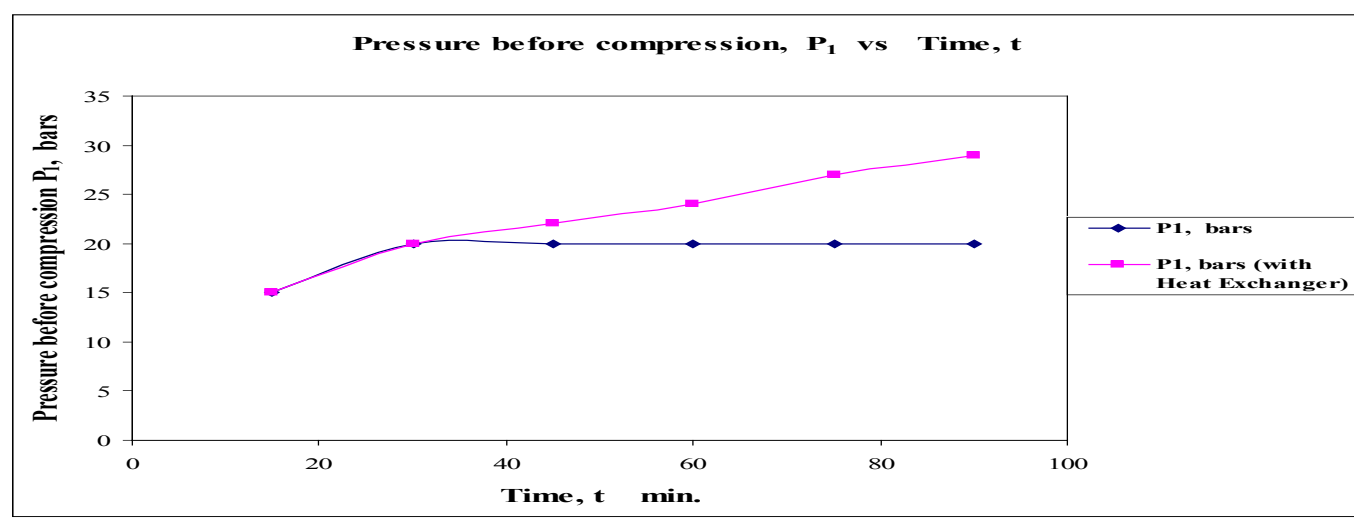

- The temperature and pressure after the compression is rising in the vapour compression refrigeration set up with the heat exchanger compared to the set up with out heat exchanger, due to better heat transfer rate because of enhanced density with the water cooled heat exchanger provided at the suction path (Ref. Fig. 5-8).

Fig.5. Temperature after compression T2, versus time t (with and without heat exchan ger)

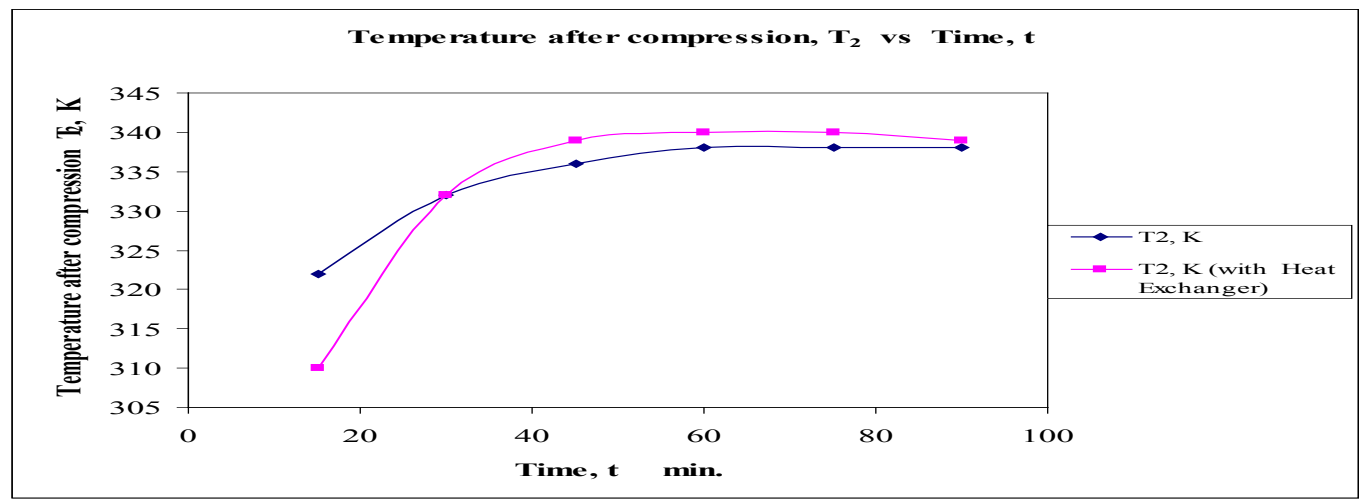


Fig.6. Pressure after compression P2, versus time $t$ (with and without heat exchanger)

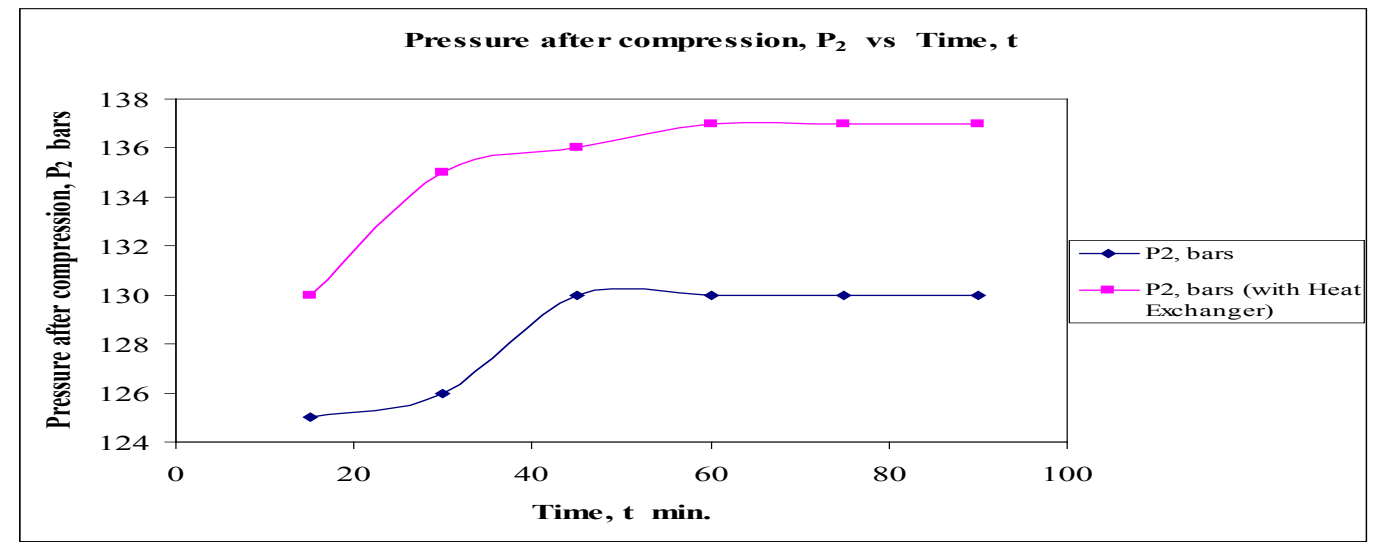

Fig.7. Temperature after condenser T3, versus time t. (with and without heat exchanger)

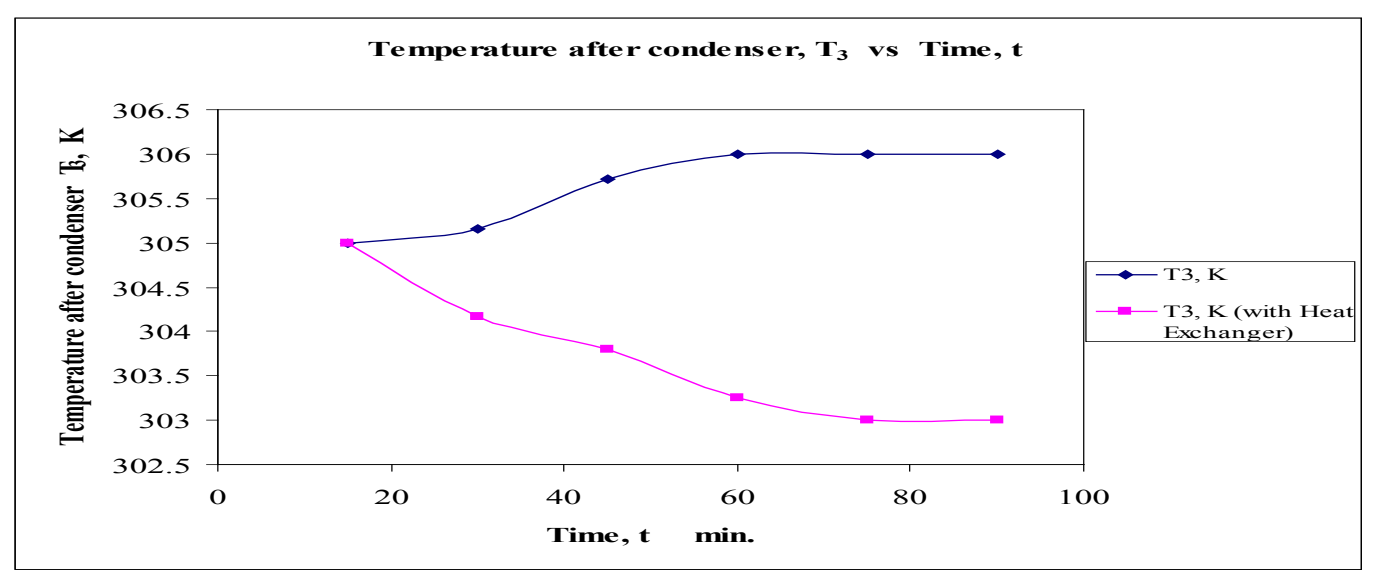

Fig.8. Pressure after condenser P3, versus time $t$ (with and without heat exchanger)

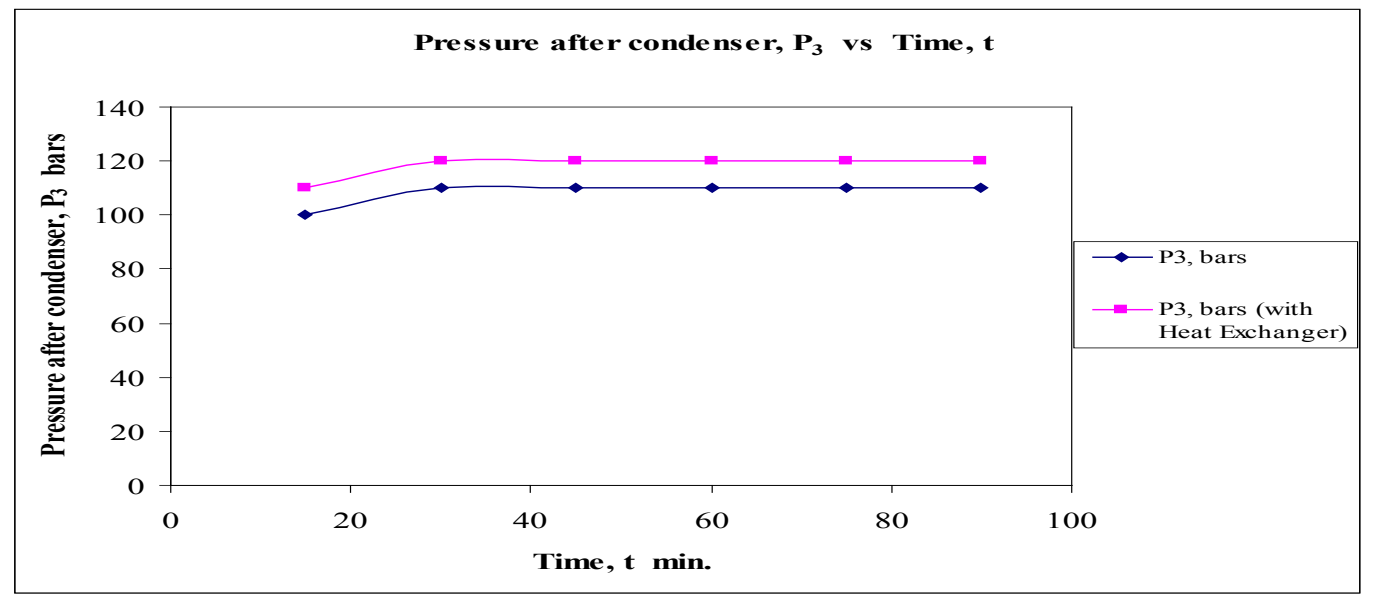

- With the heat exchanger mass density as well as mass flow rate is increased, which resulted in good heat transfer rate in the condenser and raise in the pressure (Fig.9,10).

- $\quad$ Though there is rise in the temperatures after expansion in both the cases initially, there is drastic fall in the temperatures after expansion of the refrigeration system with the heat exchanger due to the increase in mass flow rate of the refrigerant with the provision of a heat exchanger.

- After expansion the temperature of the refrigerant is seen dropping well in the instrument with the heat exchanger set up compared to the drop without heat exchanger set up. Even significant pressure drop is also seen, due to the effective mass flow of the 
refrigerant as discussed already in the previous chapters.

- As the refrigerant is cooled in suction path line due to a heat exchanger, its density increases and mass flow rate as well. This would also cause the volumetric efficiency to increase. The effect of which is observed in the coefficient of performance (Ref. Fig.9).

- The coefficient of performance increased in both the cases with time. It is observed that performance with a heat exchanger is always above than the performance with out a heat exchanger.

- As the compressor inlet temperature decreases the compressor consumption work also decreases. Because at low inlet temperatures, the energy consumption is low, which is clear from the T-S diagram, that the constant pressure lines are converged towards left and diverged towards right. Ref. Fig.10

- In both the cases of with and with out a heat exchanger the energy consumption parameter increases with time. Incase of suction path cool with a heat exchanger the energy consumption parameter is low compared to the value of energy consumption parameter with out a heat exchanger set up (Ref. Fig.10).

Fig.9. Coefficient of performance COP, versus time t. (with and without heat exchanger)

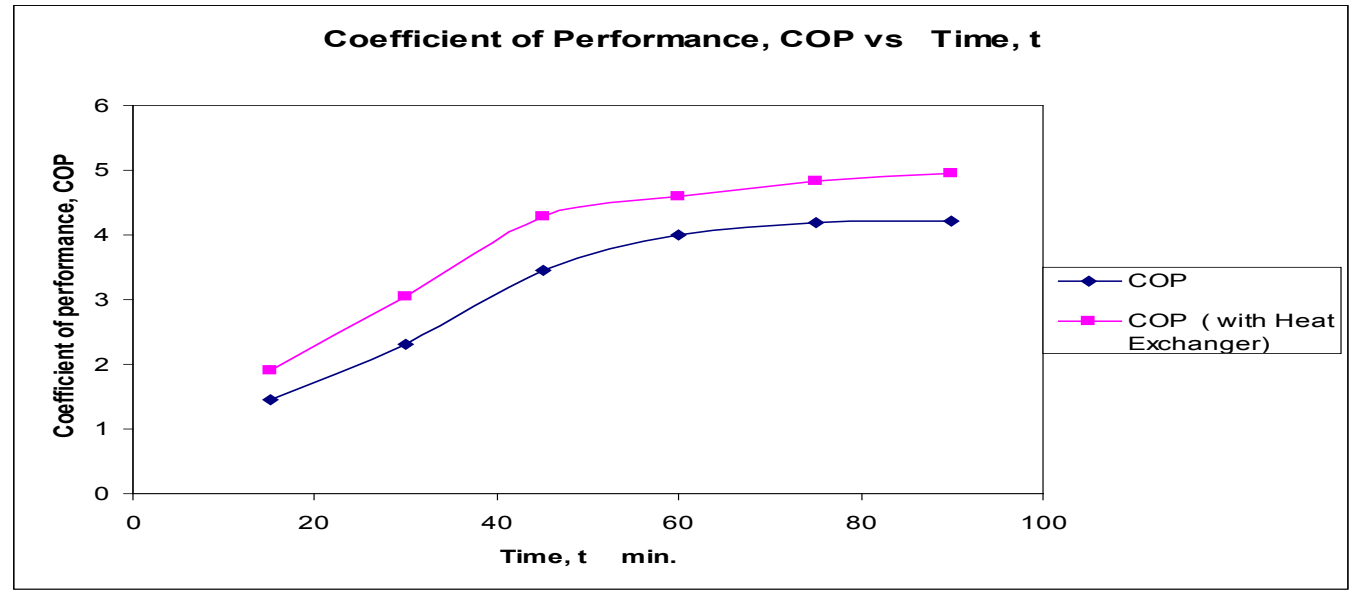

Fig.10. Energy input to the compressor, versus time, t. (with and without heat exchanger)

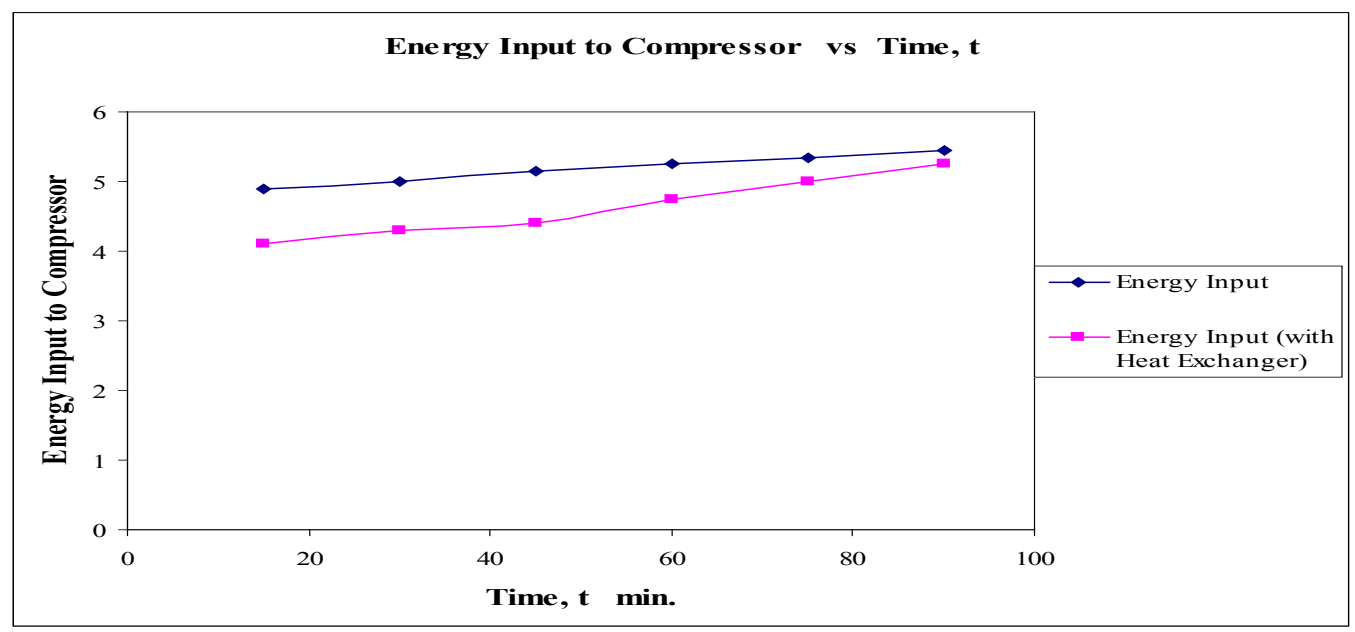

\section{Conclusions}

Compressor would consume less work when its inlet temperature is low. This is because when the inlet temperature is reduced suction path gas superheating losses are reduced. This can understood from the T-S diagram as the constant pressure lines diverge towards right. Keeping this concept in mind, an attempt had been made to make the compressor work at lower inlet temperature. By providing this heat exchanger, the reduction in the Compressor work and increase in the Coefficient of Performance of the refrigeration unit has been observed.

Though the actual COP values are much smaller compared to than Carnot COP values, it had been proved that the values obtained with heat exchanger are firmly better than that of the values with out Heat exchanger. The results of this work would be 
useful and helpful in the refrigeration industry in optimization performance of the hermetic compressor.

The suction path line cooling with heat exchanger allows improvement of compressor energy performance since, mass flow rate is increasing and input power is decreasing. With the heat exchanger the refrigerant is cooled, its density increases and mass flow rate as well, which would raise the volumetric efficiency as well.

Although in both the cases of with and with out a heat exchanger the energy consumption parameter increases with time, incase of suction path gas cool with a heat exchanger the energy consumption parameter is low compared to with out a heat exchanger set up. Because as the compressor inlet temperature decreases the compressor consumption work also decreases.

At the lower compressor inlet temperatures, the energy consumption by the compressor is low; or Compressor would consume less work when its inlet temperature is low which can be understood from the T-S diagram, that the constant pressure lines are converged towards left and diverged towards right. The pressure of the refrigerant after evaporator and before compression is more with the heat exchanger set up compared to the set up with out heat exchanger due to the enhanced mass flow rate and density. The required refrigeration temperature had been achieved with in less time when compared to the refrigeration unit working without heat exchanger. In spite of the call by some researchers, as long as a quarter century ago, for the need to understand the influence of heat transfer and start modeling the phenomenon in reciprocating compressors, the author feels there is still some complacency about its importance. As implied in this work, it is perceived as a material technology as the main focus aimed to develop new materials for improving mass flow in the compressor. Hence serious effort appears to be lacking both at the fundamental level in understanding the mechanism enough to enable development of reliable heat transfer correlations and at the application level to enable development of easy, quick and reliable procedures for predicting its impact in compressor performance. To go about the details into this is beyond the scope of this work.

\section{References}

1 - Akella Suresh, Rao NJ, Venugopal PV, Venkateswarlu K and Manohar TJ (1986) An experimental method for design and performance evaluation of a hermetic compressor. Proc. 1986 Int. Compressor Eng. Conf. Purdue. 2, 428-443.

2- Edison G, Suresh A and Narayana Rao K (2009) Effect of suction line cooling by incorporating a heat exchanger before a compressor to enhance COP of refrigerator. Int. J. Mech. \& Automobile Eng. (IJMAE). 1(1), 01-07.

3. Fabian Fagotti and Alvaro T Prata (1998) A new correlation for instantaneous Heat transfer between Gas and cylinder in reciprocating compressors. Proc. Int. Compressor Technol. Conf., Purdue, West Lafayette, USA. pp: 605-610

4- John J Jacobs (1978) Analytic and experimental techniques for evaluating compressor performance losses. Ray W.Herrick Lab., Purdue Univ., West Lafayette, Indiana. pp: 22-30.

5• McGovern JA (1990) Utilization of volumetric displacement in reciprocating compressors. Proc. Int. Compressor Technol. Conf., Purdue, West Lafayette, USA. pp: 254-263.

6• Roland Aigner and Herbert Steinrück (2007) Modelling fluid dynamics, Heat transferand valve dynamics in a reciprocating compressor'institute of fluid dynamics and heat transfer. Vienna Univ. Technol., Vienna Austria $5^{\text {th }}$ Conf. EFRC. 3, 21-23, pp: 171-180.

7- Suresh Akella, Rao NJ, Venugopal EV and Manohar TJ (1986) An experimental method for design and performance evalution of a hermetic compressor. Proc. 1986 Int. Compressor Eng. Conf., Purdue. 1, 428-443.

8- Suresh Akella, Rao NJ, Venugopal EV and Manohar TJ (1988) Performance optimization of a 1.5 ton hermetically sealed compressor through parameter design. Proc. 1988 Int. Compressor Eng. Conf., Purdue. 2, 520-525. 